\title{
Correction to: A New Species of Ctenomys (Rodentia: Ctenomyidae) from Patagonia Related to C. sociabilis
}

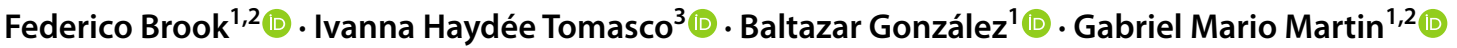 \\ Published online: 4 December 2021 \\ ๑) Springer Science+Business Media, LLC, part of Springer Nature 2021
}

Correction to: Journal of Mammalian Evolution https://doi.org/10.1007/s10914-021-09570-9

The original version of this article contained some errors with the GenBank accession numbers assigned to samples in the Molecular Analysis in the Material and Methods section and the omission of a collection acronym in Appendix 1.

\section{Material and Methods}

\section{Molecular analyses}

Two unidentified Ctenomys species were not mentioned in the text and were referred to as sp. 1 and sp. 2 in Fig. 8. Their GenBank accession numbers were erroneously assigned to two specimens of Ctenomys plebiscitum sp. nov.: LIEBM-1768 and LIEB-M-1771. The correct GenBank accession number of Ctenomys sp. 1 is HM777503 (corresponding to specimen PNG1201 from Pichiñan, referred to as C. contrerasi navonae in Teta and D'Elía 2020), and the correct GenBank accession number of Ctenomys sp. 2 is

The original article can be found online at https://doi.org/10.1007/ s10914-021-09570-9.

Federico Brook

brook.federico@gmail.com

1 Centro de Investigacion Esquel de Montaña Y Estepa Patagonica (CIEMEP), Consejo Nacional de Investigaciones Cientificas Y Tecnicas (CONICET), Universidad Nacional de La Patagonia "San Juan Bosco" (UNPSJB) Esquel, Chubut, Roca 780, Esquel, Argentina

2 Laboratorio de Investigaciones en Evolucion Y Biodiversidad, Facultad de Ciencias Naturales Y Ciencias de La Salud. Sede Esquel, UNPSJB. Ruta Nacional, 259 km 16.41, Esquel, Argentina

3 Departamento de Ecologia Y Evolucion, Facultad de Ciencias, Universidad de La Republica, Igua 4225, 11400 Montevideo, Uruguay
HM777505 (corresponding to specimen PNG191 from Talagapa, referred to as sp6 in Parada et al. 2011). The correct GenBank accession numbers for the two specimens of Ctenomys plebiscitum sp. nov. mentioned above are MZ129292 for voucher specimen LIEB-M-1768 and MZ129293 for voucher LIEB-M-1771.

\section{Appendix 1}

In the list of collections of analyzed specimens, the acronym for the Universidad Austral de Chile (UACH) was accidentally omitted.

\section{References}

Parada A, D'Elía G, Bidau CJ, Lessa EP (2011) Species groups and the evolutionary diversification of tuco-tucos, genus Ctenomys (Rodentia: Ctenomyidae). J Mammal 92:671-682. https://doi.org/ 10.1644/10-mamm-a-121.1

Teta P, D'Elía G (2020) Uncovering the species diversity of subterranean rodents at the end of the World: three new species of Patagonian tuco-tucos (Rodentia, Hystricomorpha, Ctenomys). PeerJ 8:e9259. https://doi.org/10.7717/peerj.9259 